\title{
Molecular characterization of Trichinella spiralis galectin and its participation in larval invasion of host's intestinal epithelial cells
}

\author{
Jia Xu ${ }^{1}$, Fan Yang ${ }^{2}$, Da Qi Yang ${ }^{2}$, Peng Jiang ${ }^{1}$, Ruo Dan Liu ${ }^{1}$, Xi Zhang ${ }^{1}$, Jing Cui ${ }^{*}$ and Zhong Quan Wang ${ }^{\text {** }}$
}

\begin{abstract}
The aim of this study was to study the molecular characteristics of Trichinella spiralis galectin (Tsgal) and interactions between Tsgal and host's intestinal epithelial cells (IECs). The functional domain of Tsgal was cloned and expressed in an E. coli system. The Tsgal was $97.1 \%$ identity to the galectin of T. nativa and $20.8 \%$ identity to the galectin-8 of humans. Conserved domain analysis revealed that Tsgal belongs to TR-type galectin and has two carbon recognized domain. The rTsgal with $29.1 \mathrm{kDa}$ could be recognized by T. spiralis-infected mice at 42 days post-infection (dpi). The transcription and expression of Tsgal gene was detected by RT-PCR and Western blotting in all T. spiralis developmental stages (intestinal infective larvae, adult worms, newborn larvae, and muscle larvae). The IFA results revealed that Tsgal was mainly located at the cuticles and stichosomes of T. spiralis larvae (ML, IIL and NBL). The rTsgal had hemagglutinating function for erythrocytes from human, rabbit and mouse. The results of Far Western blot and confocal microscopy indicated there was specific binding between rTsgal and IECS, and the binding was located the membrane and cytoplasm of the IECs. Out of four sugars (sucrose, glucose, lactose and maltose), only lactose was able to inhibit the rTsgal agglutinating role for human type B erythrocytes. Moreover, the rTsgal could promote the larval invasion of IECs, while the anti-rTsgal serum inhibited the larval invasion. These results demonstrated that Tsgal might participate in the T. spiralis invasion of intestinal epithelium in early infection stage.
\end{abstract}

\section{Introduction}

Trichinellosis is an important zoonotic disease resulted from the parasitic nematode Trichinella [1]. This zoonosis is widely distributed in many kinds of mammalian species, including humans [2]. Human infections are mainly due to eating raw or uncooked animal meat infected with Trichinella spiralis [3-5]. Since outbreaks of human trichinellosis has been reported in many countries, this disease has become a public health concern and regarded as a re-emerging or emerging disease [6, 7]. Thus, to prevent the swine from Trichinella infection is necessary for ensuring meat food safety and the public health $[8,9]$.

T. spiralis muscle larvae (ML) are liberated from the capsules in stomach after infected meat is digested by

\footnotetext{
*Correspondence: cuij@zzu.edu.cn; wangzq2015@126.com

${ }^{1}$ Department of Parasitology, Medical College, Zhengzhou University, Zhengzhou 450052, China

Full list of author information is available at the end of the article
}

gastric fluid, and then develop into intestine infective larvae (IIL) after activation by bile and enteral contents at 0.9 hours post-infection (hpi) $[10,11]$. The IIL larvae penetrate into the intestinal epithelium, and undergo the four molts to develop to adult worms (AW) at $31 \mathrm{hpi}$. After mating in the intestine, the female adults shed newborn larvae (NBL) which enter the venules and lymphatic vessels, and then spread throughout the body via blood circulation until they reach the final parasitizing skeletal muscles and develop into the encapsulated ML [12]. The ML can survive from about 1-2 to 10-15 years in host without obvious damage [13, 14]. However, the mechanism of T. spiralis invasion of intestinal epithelium has not been clarified completely. The studies on larval invasion mechanism will be valuable to develop the novel vaccine candidate and drug targets against Trichinella infection [8].

Galectins are characterized by a unique carbon recognized domain (CRD) sequence motif binding to 
$\beta$-galactoside, and constitute an evolutionary conserved family. They are ubiquitous and structurally in eukaryotic taxa, including vertebrate, invertebrate, fungus and sponges [15]. Based on structural features, three types of galectin proteins have been identified, including proto-type, chimera-type and tandem repeat-type (TR) [16]. Proto-type galectins are homodimers containing a single CRD without covalent bond. The chimera types have a C-terminal CRD with the opposite $\mathrm{N}$-terminal domain rich in proline and glycine. While the TR-type consisted of two CRDs which are connected with a functional linker peptide. The subtypes of mammalian galectins were named according to the order of their discovery. Thus far, 15 galectins have been identified in mammal, including nine proto-type (galectins-1, -2, -5, -7, -10, -11, -13, -14 and -15), five TR-types (galectins-4, $-6,-8,-9,-12$ ) and only one chimera-type (galectin-3) [17].

Several galectins or galectin-like proteins have been described in some parasites. They are speculated to play a role in the invasion process and immunomodulation. The galectin derived from Dirofilaria immitis had been demonstrated to active the host fibrinolytic system and stimulate the proliferation of smooth muscle cells and degradation of the extracellular matrix (ECM), which is related to the parasite surviving in the host [18]. In the experimental autoimmune encephalomyelitis (EAE) model, treatment with galectin from Toxascaris leonine could enhance the EAE severity and antibody production which resulted in the attenuation of EAE remission [19]. However, another previous study on inflammatory bowel disease (IBD) model demonstrated that galectin of Toxascaris leonine deliver a beneficial effect on dextran sodium sulfate (DSS) by exhibiting significantly increase of the levels of TGF- $\beta$ and IL-10 [20]. The expression level of galectin-10 mRNA of Angiostrongylus cantonensis was upregulated after being stimulated with $\mathrm{H}_{2} \mathrm{O}_{2}$, which indicated the natural galectin can be induced under the reactive oxygen stress [21]. The recombinant galectins from Haemonchus contortus had been indicated to be a potential vaccine target to protect goats from $H$. contortus infection [22]. However, studies on biological characteristics and functions of $T$. spiralis galectins have not been reported in the references available up to date.

One galectin from T. spiralis (Tsgal, GenBank accession No. EFV62290) has been identified in the ML surface protein by immunoproteomics $[23,24]$. The aim of this study is to identify the biological characteristics and functions of Tsgal in T. spiralis larval invasion of host's intestinal epithelial cells.

\section{Materials and methods}

\section{Bioinformatics analysis of Tsgal}

The bioanalysis software and websites are used to analyze the sequence of Tsgal as described [25, 26]. The physical and chemical properties of amino acid sequence of Tsgal were predicted through Protparam Server, the signal peptide was predicted by using SignalP 4.1 Server, and the transmembrane domain was predicted on TMHMM Server v. 2.0. The sequence was submitted to BcePred Prediction Server to predict the antigenic epitopes of Tsgal. The domain analysis of Tsgal was performed using Conserved Domain database of NCBI. The amino acid sequence of Tsgal was alignmented with galectins from other organisms using the clustal X. Galectin sequences from other species were downloaded from NCBI. The GenBank accession numbers of other galectins are as follow: T. nativa (KRZ49476), T. murrelli (KRX35770.1), T. nelsoni (KRX15368.1), T. patagoniensis (KRY16872.1), T. pseudospiralis (KRY89534.1), Trichinella sp. T6 (KRX72992.1), Trichinella sp. T8 (KRZ90044.1), Trichinella sp. T9 (KRX52357.1), T. zimbabwensis gal lec-3 (KRZ13804.1), Trichostrongylus colubriformis (AAD11971.1), Caenorhabditis elegans (AAB87718.1), Caenorhabditis elegans (NP_496159.1), Brugia malayi (AAF37721.1), Haemonchus contortus (AAB88823.1), Onchocerca volvulus (AAD00843.1), Dirofilaria immitis (AAF37720.1), Toxascaris Leonina (4HL0_B Chain B, Crystal Structure Of Full-length), Homo gal-8 (AAF19370) and Mus gal-6 (NP_034837). The phylogenetic tree of these galectin sequences was constructed using MEGA7.0. The phylogeny was constructed by using the maximum parsimony method [27].

\section{Parasite, experimental animal and cells}

Trichinella spiralis strain (ISS534) was isolated from domestic pigs in central China, this strain was maintained in our department by passage in mice. Female BALB/c mice aged 35 days old were purchased from the Henan Provincial Experimental Animal Center. The intestinal epithelial cells (IEC) were isolated from the intestines of normal BALB/c mice in our laboratory [28] and the primary culture cells at passage 8 were used for the invasion assay. Previous studies have showed that the IECs are susceptible to T. spiralis invasion [29]; whereas the mouse striated muscle myoblast cells $(\mathrm{C} 2 \mathrm{C} 12)$ were resistant to the invasion and applied as negative control [29].

\section{Worm collection and protein preparation}

The ML were recovered at 42 days post-infection (dpi) by artificial digestion of infected mouse carcasses with $0.33 \%$ pepsin and $1 \% \mathrm{HCl}$ as described [30]. T. spiralis IIL 
were collected from mouse small intestines at 6 hpi [24], and intestinal AW were collected at 3 and $6 \mathrm{dpi}$ as previously described [31]. The NBLwere collected from the 6 dpi adult females which was cultured in $5 \% \mathrm{CO}_{2}$ at $37^{\circ} \mathrm{C}$ for $18 \mathrm{~h}$ in the PRMI-1640 medium containing 10\% fetal bovine serum (FBS; Gibco) [32]. The excretory/secretory (ES) proteins of ML and soluble crude somatic proteins of ML, IIL, AW, and NBL were prepared [33, 34]. The protein concentration of ES proteins and somatic proteins was measured by the Bradford method [35].

\section{Cloning, expression of recombinant Tsgal protein}

Total RNA was obtained from the ML with Trizol (Invitrogen, USA) according the standard operation instructions supplied by the manufacure. The first-strand synthesis of cDNA was performed using AMV reverse transcriptase (Promega, USA). Tsgal gene was amplified using PCR with specific primers carrying BamHI and HindIII restriction enzyme sites (in italics) (5'-CACCAT CACCATCACGGATCCAAAGTTCCGTATTTAGCC AA-3', 5'-CAAGCTCAGCTAATTAAGCTTTCATTC TAAATGAATCAACT-3'). PCR products were cloned into the prokaryotic expression vector $\mathrm{pQE}-80 \mathrm{~L}$ vector using ClonExpress ${ }^{\mathrm{TM}}$ II one-step clon kit (Vazyme, China) following the instruction, the recombinant plasmid $\mathrm{pQE}$ 80L/Tsgal was then transferred into the Escherichia coli BL21 (DE3) (Novagen). The expression of rTsgal protein was induced for $6 \mathrm{~h}$ at $37^{\circ} \mathrm{C}$ by using $0.5 \mathrm{mM}$ IPTG. The rTsgal was found in the supernatant, subsequently purified with Ni-NTA-Sefinose resin (Sangon Biotech Co., Shanghai, China) [36]. The concentration of purified rTsgal was determined, then analyzed by SDS-PAGE with $12 \%$ acrylamide separating gel [37].

\section{Preparation of anti-rTsgal serum}

Fifty BALB/c mice were immunized by subcutaneous injection of $20 \mu \mathrm{g}$ rTsgal protein emulsified with complete Freund's adjuvant. Three boost immunizations were performed with the same amount of rTsgal emulsified with incomplete Freund's adjuvant at 10-day intervals $[14,38]$. The immunized mice were bled on the 7 th day after the last immunization, and the sera were isolated.

\section{Western blot analysis}

Samples containing somatic proteins of ML, IIL, AW and NBL, ML ES proteins and rTsgal protein were separated by SDS-PAGE with a $12 \%$ separating gel and then were transferred onto the polyvinylidene difluoride (PVDF) membranes using a Mini Trans-Blot ${ }^{\circledR}$ Cell (Bio-Rad, China) at $250 \mathrm{~mA}$ for $1.5 \mathrm{~h}$ [39]. The membrane was sliced into strips and then blocked for $2 \mathrm{~h}$ at room temperature by $5 \%$ skim milk in tris-buffered saline- $0.05 \%$ Tween-20 (TBST). After washing with TBST for three times, the strips were incubated at $37^{\circ} \mathrm{C}$ for $1 \mathrm{~h}$ with 1:100 dilutions of different sera (anti-rTsgal serum, $T$. spiralis-infected mouse serum and pre-immune serum). Following washing, strips were incubated at $37^{\circ} \mathrm{C}$ for $1 \mathrm{~h}$ with 1:5000 dilutions of anti-mouse IgG-HRP-conjugate (Southern Biotechnology, USA). After the final washes, the strips were colored with 3, 3'-diaminobenzidine tetrahydrochloride (DAB; Sigma) [40, 41].

\section{RT-PCR analysis of Tsgal gene transcription}

Total RNA was extracted from $T$. spiralis different phases, including IIL, AW, NBL and ML. The transcription of Tsgal gene at each stage was observed by RT-PCR as described [29]. The positive control was performed with amplifying T. spiralis GAPDH (GenBank accession No. AF452239).

\section{Immunofluorescent assay (IFA)}

IFA was used to locate the position of Tsgal protein in T. spiralis. The whole ML, IIL, AW and NBL were fixed with acetone, the ML and AW were also fixed in paraformaldehyde and embedded in paraffin. Then $2-\mu \mathrm{m}$ sections of this nematode were prepared by using the microtome-cutting. The whole parasites and sections were first blocked with $5 \%$ goat serum in PBS and then incubated for $1 \mathrm{~h}$ at $37^{\circ} \mathrm{C}$ with anti-rTsgal serum diluted at 1:10 [42]. Pre-immune normal serum was utilized as negative control and infection serum as positive control. Following washes, the whole parasites and sections were incubated with 1:100 dilutions of a goat anti-mouse IgG-FITC conjugate (Santa Cruz, USA). Finally, the parasites and sections were washed for three times with PBS, and observed with a fluorescent microscope (Olympus, Japan) [43].

\section{Far Western analysis}

In order to analyze the protein interaction between Tsgal and IECs, the protein samples of IECs were prepared and separated by SDS-PAGE with $12 \%$ resolving gels as described [44]. After electrophoresis, the IEC proteins were transferred to PVDF membrane, and incubated with $20 \mu \mathrm{g} / \mathrm{mL}$ of the rTsgal for $1 \mathrm{~h}$ at $37^{\circ} \mathrm{C}$. The negative control was performed by using PBS instead of rTsgal protein. The membrane was first probed by the primary antibodies (anti-rTsgal serum, mouse infection serum or pre-immune serum) at $37^{\circ} \mathrm{C}$ for $1 \mathrm{~h}$. After washing with PBS for three times, the membrane was then probed with the anti-mouse IgG-HRP conjugate as secondary antibodies at $37^{\circ} \mathrm{C}$ for $1 \mathrm{~h}$, and lastly dyed with the 3,3'-diaminobenzidine tetrahydrochloride (DAB, Sigma) [45]. 


\section{Cell immunostaining and confocal microscopy}

For confocal microscopy, the IECs were cultured in a 6-well cell culture plate. After cells were grown to confluence, the IECs were fixed in acetone for $10 \mathrm{~min}$ and blocked for $2 \mathrm{~h}$ at $37{ }^{\circ} \mathrm{C}$ with $5 \%$ goat serum for $30 \mathrm{~min}$, subsequently incubated with $20 \mu \mathrm{g} / \mathrm{mL}$ rTsgal (PBS as negative control). After being rinsed, the IECs were probed at $37^{\circ} \mathrm{C}$ for $1 \mathrm{~h}$ by using anti-rTsgal serum, infection serum or pre-immune serum. After washes again, the IECs were probed by anti-mouse IgG-FITC conjugate at $37^{\circ} \mathrm{C}$ for $1 \mathrm{~h}$ [44]. Imagines were captured by using an Olympus FV1200 laser scanning microscope and analyzed by using Olympus Fluoview software.

Hemagglutination activity assay and sugar inhibition assay The hemagglutination activity of galectins may play a key role for affecting cellular activation and function through sugar binding- dependent mechanisms in the process of parasite invasion of hosts $[20,48]$. To determine the Tsgal activity, hemagglutination and sugar-binding assay were used in this study. Human blood samples with A, B, O and $A B$ types were generously supplied by the Henan Red Cross; blood samples were also collected from rabbit and mice in this study. Erythrocytes were centrifuged at $350 \mathrm{~g}$ for $10 \mathrm{~min}$, followed by washing with $\mathrm{pH} 7.0$ sterilized saline solution for three times. Then, the erythrocytes were re-suspended in $2 \%$ saline solution. Hemagglutination activity assay were conducted as described with slightly modification [46, 47]. First, $25 \mu \mathrm{L}$ of different dilutions $(0-400 \mu \mathrm{g} / \mathrm{mL})$ of the rTsgal was added into the 96-well plate, and then $25 \mu \mathrm{L}$ of $2 \%$ suspensions of erythrocytes were also added to each well. The experiment was carried out in triplicate. The plate was incubated in the room temperature for $1 \mathrm{~h}$, complete agglutination was observed by naked eye, the lowest dose of the rTsgal for inducing agglutination was recorded.

Sugar inhibition assay was performed according to the previous studies [48] with slight modification. Four different carbohydrates including lactose, glucose, maltose and sucrose were used in our study. The rTsgal $(100 \mu \mathrm{g} /$ $\mathrm{mL}$ ) was added to the 96 -well plates, $25 \mu \mathrm{L}$ different dilutions (100-400 mM) of carbohydrates were subsequently added into the well. Following being incubated for $1 \mathrm{~h}$ at the room temperature, $2 \%$ suspensions of type B human erythrocytes were added and incubated in the room temperature another $1 \mathrm{~h}$ to observe the hemagglutination. Two control experiments were conducted without carbohydrate or rTsgal which was replaced with PBS, respectively.

\section{The in vitro invasion assay}

The in vitro $T$. spiralis IIL invasion assay was performed to evaluate the effects of anti-rTsgal serum on larval invasion of intestinal epithelium $[49,50]$. In brief, The ML was activated into the IIL by $5 \%$ swine bile at $37{ }^{\circ} \mathrm{C}$ for $2 \mathrm{~h}$ [11]. The IEC cell monolayers were overlaid with 100 IIL suspended in the semisolid medium (DMEM supplemented with L-glutamine, $15 \mathrm{mM}$ HEPES, 1.75\% agarose). The media were supplemented with different dilutions (1:10-1:800) of anti-rTsgal serum, pre-immune serum or infection serum. After incubation at $5 \% \mathrm{CO}_{2}$ at $37^{\circ} \mathrm{C}$ for $2 \mathrm{~h}$, the larval invasion of monolayer was examined and counted. The larvae still suspended in the semisolid medium was counted as non-invaded larvae, while the invaded and migrated in the monolayer were defined as invaded larvae [51]. Besides, to investigate the effects of the rTsgal protein on the larval invasion, different concentration $(0-15 \mu \mathrm{g} / \mathrm{mL})$ of the rTsgal was also used in the invasion assay [29].

\section{Statistical analysis}

The data were statistically analyzed with the aid of SPSS 17.0 soft-ware. The values were presented as mean \pm standard deviation (SD). The differences of the percentage of invaded larvae in IECs among three groups of different serum were compared by using Chi square test. The association between larval invasion and rTsgal dose was analyzed by a linear regression. Differences of larval invasion rate in the presence or absence of rTsgal were compared using one-way ANOVA. The level of statistical difference was $P<0.05$.

\section{Results}

\section{Bioinformatics analysis of Tsgal}

The complete CDS of Tsgal (XP_003381656.1) contains 855 bp encoding 284 amino acids. Signal P 4.1 Server prediction showed that there is a signal peptide at the first $15^{\text {th }}$ amino acids. TMHMM server analysis revealed no transmembrane domain of Tsgal. The Tsgal had seven potential antigenic epitopes (aa 85-95, 108-112, 153$160,167-170,201-209,220-225$ and 230-234). Conserved domain analysis revealed that the Tsgal had two CRD located at 23-150 aa and 165-282 aa, and identified as TR-type. In order to amplify the complete functional domain of Tsgal gene, a pair of specific PCR primers were designed to amplify the fragment with $61-855 \mathrm{bp}$ in this study, and this fragment was $795 \mathrm{bp}$ and encoded 264 amino acids with a molecular weight (MW) of $29.1 \mathrm{kDa}$.

\section{Sequence alignment and phylogenetic analysis of Tsgal}

The homology comparison of Tsgal amino acid sequences with those of several nematodes, mouse and human was shown in Figure 1. The conserved motifs HFNPRF and WGXEXR were located in the C-terminal CRD. The amino acid sequences of the Tsgal from Trichinella spiralis had $97.1 \%$ identity with the galectin of $T$. nativa, 


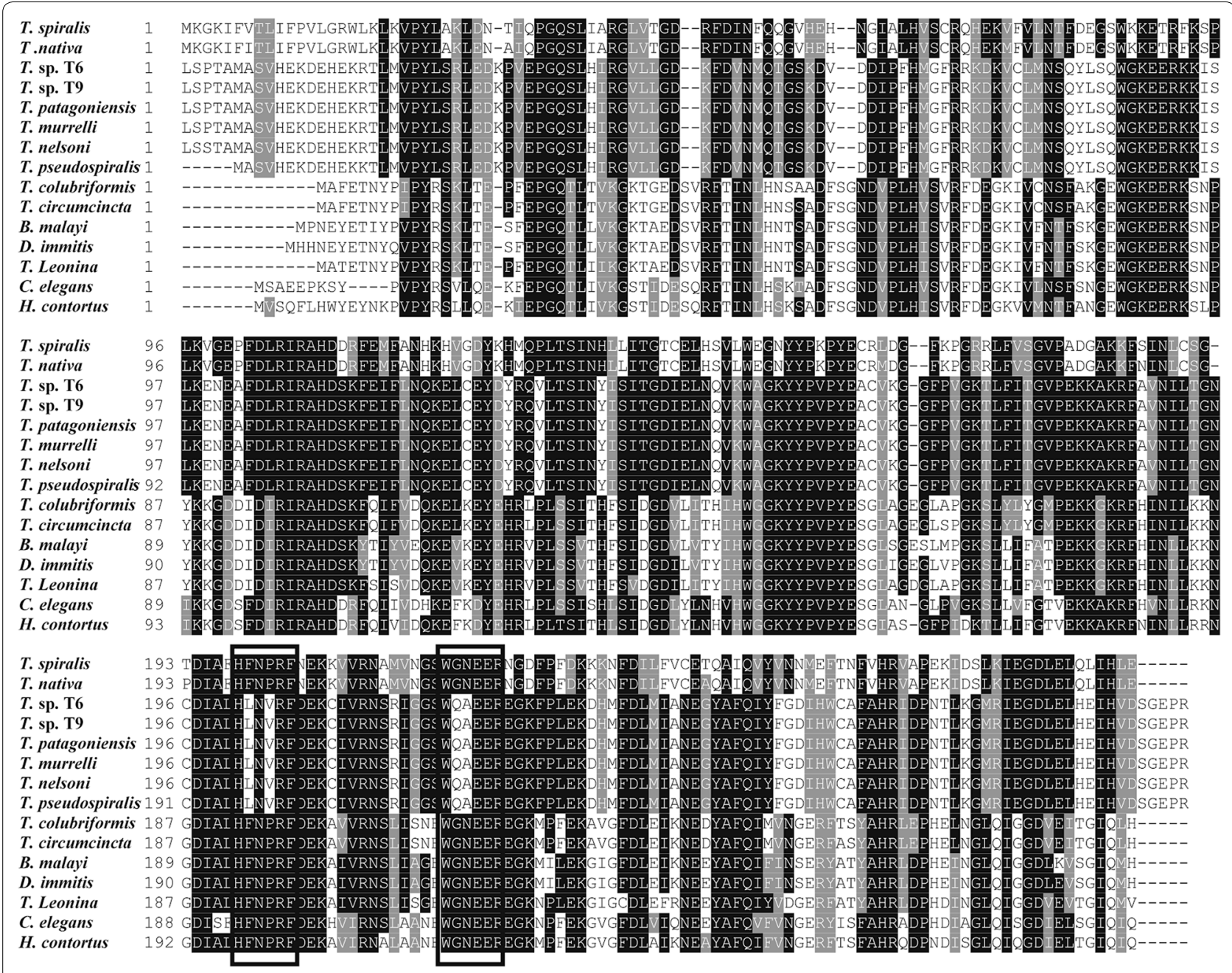

Figure 1 Sequence alignment of Trichinella spiralis galectins (XP003381656.1) with other Trichinella species and other organisms. The multiple sequence alignment was performed in the Clustal X and displayed using BOXSHADE. The conserved regions HFVRF and WGXEXR motifs of galectins were shown in box. Black shade indicated that residues identical to Tsgal, and conservative substitutions were shaded grey.

$68.8 \%$ identity with gal lec-3 of T. zimbabwensis. At different genus level, Tsgal was found to be $41.4 \%$ identity with galectin of Haemonchus contortus, and $36.0 \%$ identity with the galectin of Brugia malayi. Furthermore, some galectin subtypes of mouse and human were also compared with Tsgal, $7.8-22.1 \%$ similarity was found between Tsgal and galectin subtypes of human and mice (Table 1). The phylogenetic analysis of the galectins of various organisms supported the monophyletic group of three species of Trichinella (T. spiralis, T. nativa and T. zimbabwensis) (Figure 2).

\section{Expression and purification of $\mathrm{rTsgal}$ protein}

A 795 bp amplified fragment was obtained and cloned into the $\mathrm{pQE}-80 \mathrm{~L}$ expression vector using seamless clone kit. After induction with IPTG, the fusion protein

Table 1 Similarity (\%) of amino acid sequences of Tsgal to various galectins of human and mouse

\begin{tabular}{|c|c|c|c|c|c|c|c|c|c|c|c|c|}
\hline Hosts & gal-1 & gal-2 & gal-3 & gal-4 & gal-6 & gal-7 & gal-8 & gal-9 & gal-10 & gal-12 & gal-13 & gal-16 \\
\hline Human & 12.3 & 11.4 & 15.9 & 19.7 & - & 12.7 & 20.8 & 17.9 & 7.8 & 14.8 & 8.9 & 9.9 \\
\hline Mouse & 12.3 & 11.4 & 15.6 & 18.9 & 22.1 & 12.7 & 19.1 & 17.9 & - & 14.8 & - & - \\
\hline
\end{tabular}

- Represent no sequence was recorded in NCBI. 


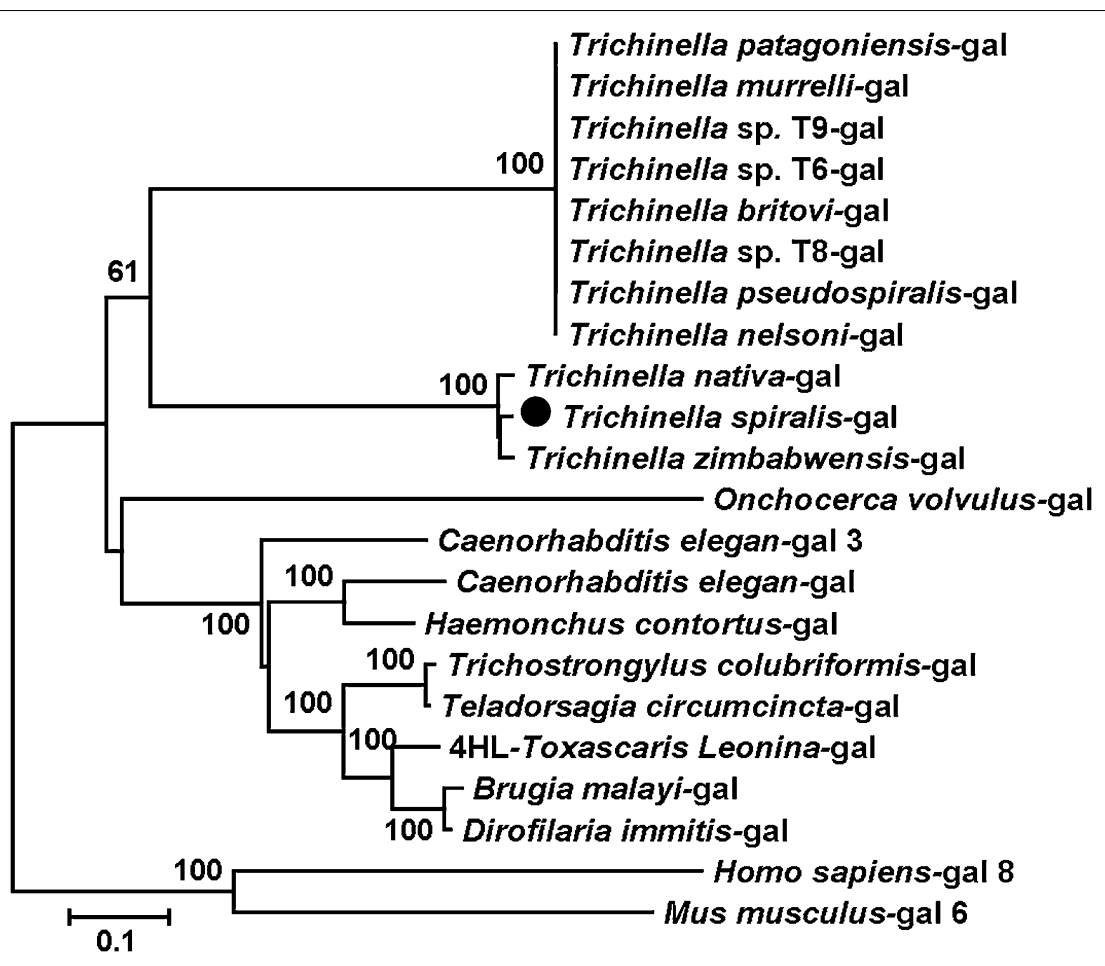

Figure 2 Phylogenetic tree of analysis of Tsgal. Phylogenetic relationship of Tsgal with galectins of other nematodes, mouse and human with maximum parsimony method and drawn with MEGA. Bootstrap values that are higher than 60 are indicated on branches. The sequence indicated with solid circle was Tsgal protein (XP003381656) cloned in this study.

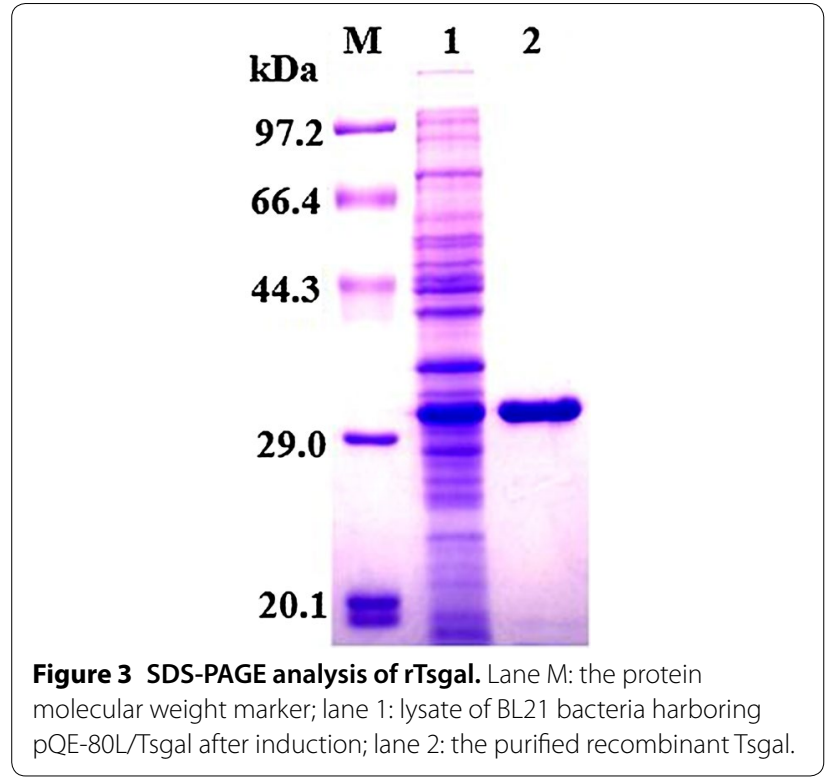

with the His-tag was expressed in E. coli BL21 harboring $\mathrm{pQE}-80 \mathrm{~L} /$ Tsgal. The rTsgal protein was purified by using Ni-NTA-Sefinose Column and a single band was observed on SDS-PAGE analysis. The MW of the rTsgal is approximately $29.1 \mathrm{kDa}$ which was congruent with its predicted size (Figure 3).

\section{Identification of rTsgal by Western blot analysis}

Western blot results revealed that the rTsgal protein was probed by anti-rTsgal serum and T. spiralis-infected mouse serum. By using anti-rTsgal serum the natural Tsgal protein was identified in somatic proteins of ML, IIL, 3 days AW, 6 days AW and NBL, but not in ML ES protein (Figure 4), demonstrating the Tsgal is one component of somatic proteins of this parasite, but not ES protein of the ML.

\section{RT-PCR analysis of Tsgal gene transcription}

The Tsgal mRNA transcript (980 bp) was observed at all T. spiralis lifecycle phases (e.g., ML, 6 h IIL, 3 and 6 days AW, and NBL). The expected band (570 bp) of GAPDH was also generated in all of the samples (Figure 5).

\section{Expression and immunolocalization of Tsgal at various phases}

The results of IFA with the whole nematode revealed that by using anti-Tsgal serum the intense immunofluorescent staining was found on the surface of the ML, IIL and NBL, weak staining was observed on the surface of AW 

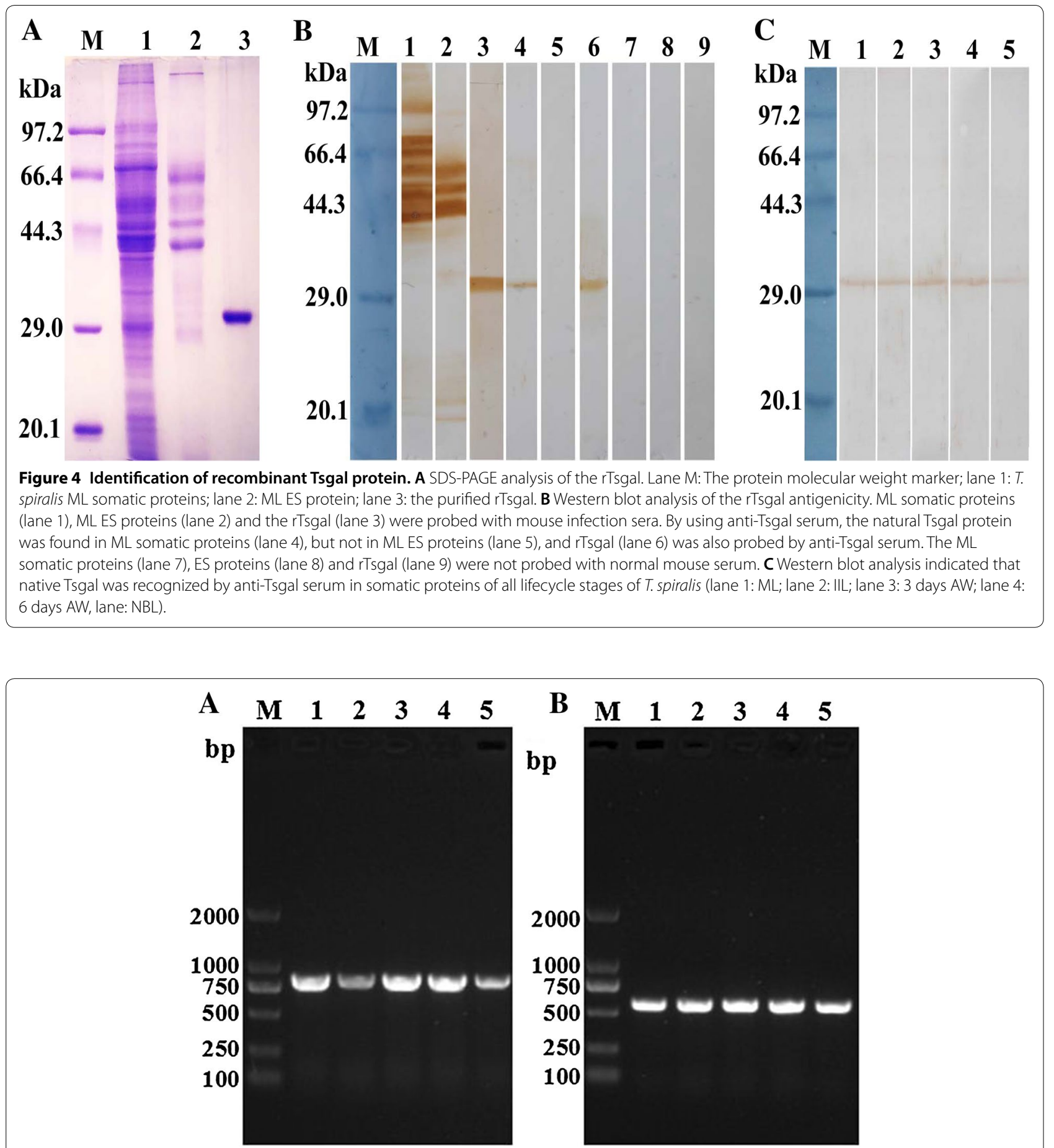

Figure 5 RT-PCR analysis of Tsgal A and GAPDH B transcription at Trichinella spiralis different developmental phases. lane M: DL2000 DNA marker; lane 1: ML; lane 2: ILL at 6 hpi; lane 3: 3 dpi AW; lane 4: 6 dpi AW; lane 5: NBL.

(Figure 6). While the nematode sections were probed with the anti-rTsgal serum, intense staining was detected at the cuticles and stichosomes of the ML. The immunostaining was also observed at the cuticle and embryos of female adult at $3 \mathrm{dpi}$.
Far Western analysis of binding of rTsgal with IEC proteins The IEC lysates were firstly analyzed with SDS-PAGE, and the results showed normal IEC proteins have about 22 bands with a molecular weight of $15.2-97.2 \mathrm{kDa}$ (Figure 7A). Far Western results showed that ten bands 


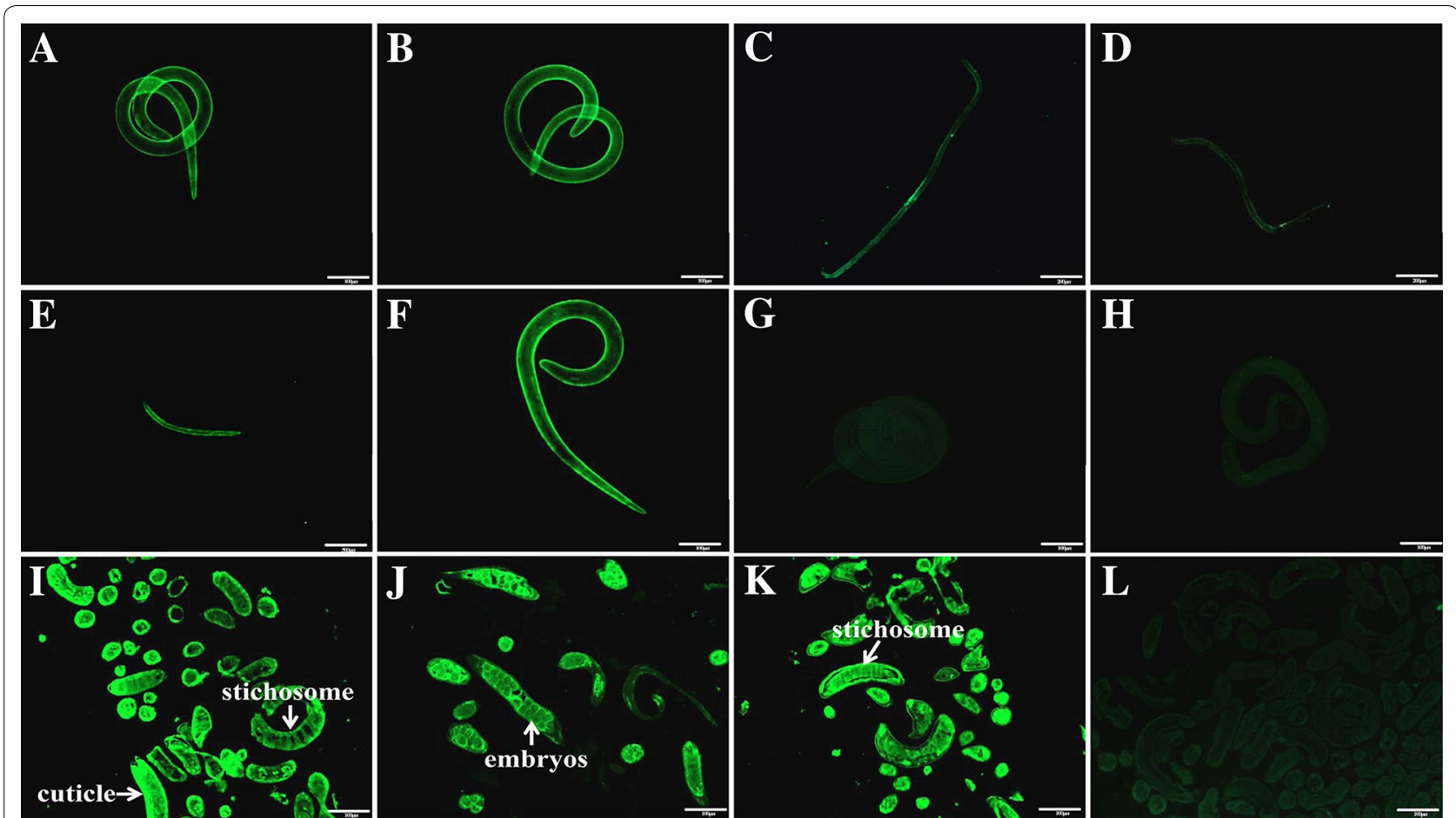

Figure 6 Expression and immunolocalization of Tsgal at T. spiralis various developmental phases. A-E: The results of IFA with intact nematodes probed by anti-rTsgal serum. The intense immunostaining was observed on the surface of $M L \mathbf{A}, I I L \mathbf{B}$ and NBL E, but slight staining was found on the surface of 3 days male $(\mathbf{C})$ and female $(\mathbf{D})$. The $M L(\mathbf{F})$ recognized by infection serum was served as a positive control; the ML incubated with normal serum (G) and PBS (H) was served as negative control. I-L Immunolocalization of Tsgal in Trichinella spiralis ML and AW using IFA with worm sections. By using anti-Tsgal serum the intense immunostaining was located at the cuticles and stichosomes of the ML (I), and embryos of female adult at $3 \mathrm{dpi}(\mathbf{J})$. The section of $\mathrm{ML}(\mathbf{K})$ recognized by infection serum as a positive control; The ML (L) not recognized by normal serum as negative controls. Scale-bars: A, B, F-L, $200 \mu \mathrm{m} ; \mathbf{C}, \mathbf{D} 100 \mu \mathrm{m} ; \mathbf{E}, 500 \mu \mathrm{m}$.

(20.5-97.2 kDa) of IEC lysates pre-incubated with rTsgal were probed by anti-rTsgal serum, and the majority of recognized bands have a MW of more than $30 \mathrm{kDa}$ (Figure 7B). However, only one band with $65.3 \mathrm{kDa}$ of IEC lysates was recognized by mouse infection serum. No bands of $\mathrm{C} 2 \mathrm{C} 12$ lysates pre-incubated with rTsgal were probed by either anti-Tsgal serum or infection serum.

\section{IFA and confocal microscopy of binding and cellular localization of rTsgal with IECs}

After the IECs were incubated with rTsgal, the fluorescent staining was detected on the surface of the IECs due to anti-rTsgal serum or infection serum, but not due to normal serum (Figure 8). Furthermore, no staining of $\mathrm{C} 2 \mathrm{C} 12$ cells incubated with rTsgal was observed by either anti-Tsgal serum or infection serum. Confocal microscopy revealed that rTsgal could bind to the IECs; the binding sites were located at the membrane and cytoplasm of the IECs (Figure 9).

\section{Hemagglutination activity of rTsgal and sugar inhibition assay}

The rTsgal was used for the hemagglutination and sugar inhibition assays, the results revealed that rTsgal has the hemagglutinating function, the minimum concentration of rTsgal agglutinating to human type $A, B, A B$ and $O$ erythrocytes was 200, 40, 100 and $100 \mu \mathrm{g} / \mathrm{mL}$, respectively; the minimum concentration to mouse and rabbit erythrocytes was $100 \mu \mathrm{g} / \mathrm{mL}$. In the sugar inhibition assay, lactose is the only carbohydrate which can inhibit the agglutination of human type B erythrocytes by rTsgal (Figure 10).

\section{Promotion or inhibition of rTsgal or anti-rTsgal serum on larval invasion of IECs}

After incubation with the IEC monolayer at $37{ }^{\circ} \mathrm{C}$ for $2 \mathrm{~h}$, the IIL invaded the monolayer were observed and counted (Figure 11). While 1:100 dilutions of antirTsgal serum, infection serum and pre-immune serum were supplemented into the medium and incubated for 


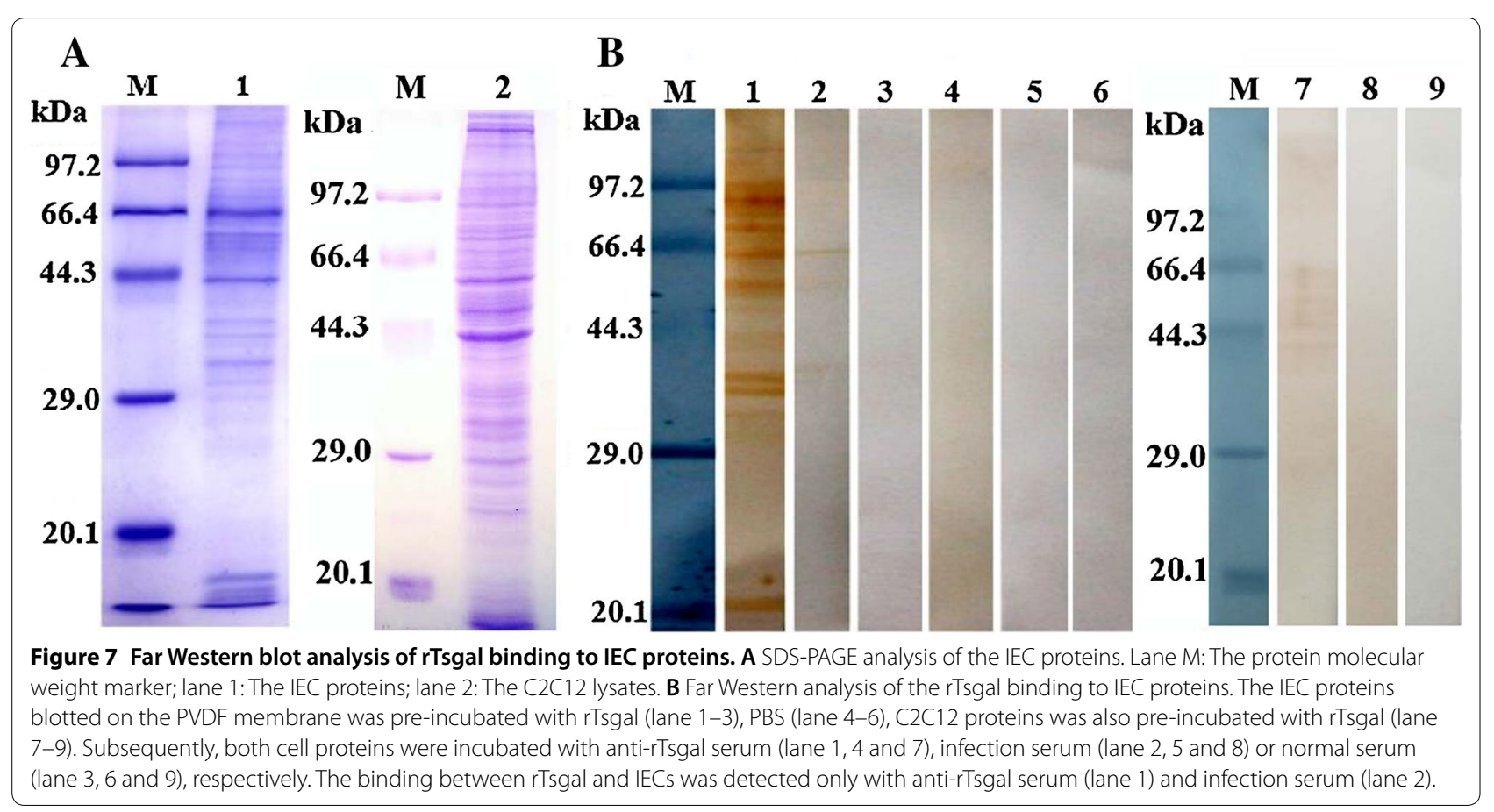

$2 \mathrm{~h}$, larvae invaded in monolayer was 32.83, 25.38 and $49.69 \%$, respectively $\left(\chi^{2}=195.915, P=0\right)$. The inhibition of anti-rTsgal serum (1:10-1:100) on the invasion was evidently higher than those of pre-immune serum $(P=0)$ (Figure 12A). Moreover, when the rTsgal was added into the medium and incubated at $37{ }^{\circ} \mathrm{C}$ for $2 \mathrm{~h}$, obvious promotion of rTsgal on larval invasion of the monolayer was found, and this promotion was the rTsgal dose-dependent $(P=0)$, and exhibited an increase trend with the increase of the rTsgal dose $(F=45.458, P=0)$ (Figure 12B).

\section{Discussion}

Galectin was widely distributed from vertebrate to invertebrate, even in fungi. In parasites, more and more galectins have been identified and exert a significant impact in the interaction between parasite and host. Helminth infection can also be modulated by the galectins of hosts and vectors, such as $H$. contortus [52], Leishmania major [53] and Schistosoma mansoni [54]. The galectins have also been isolated from nematode parasite Teladorsagia circumcincta and Toxascaris leonina, their structures and function has been characterized [55-57]. However, the galectins of $T$. spiralis have not been reported up to now.

In the present study, the functional domain of Tsgal gene was cloned from $T$. spiralis ML and expressed successfully by using $E$. coli expression system, the MW of the rTsgal protein is approximately $29.1 \mathrm{kDa}$ in line with the expected size. A 15 amino acids signal peptide was predicted in Tsgal gene, while most galectins lack a typical secretion signal peptide [58]. The Tsgal is identified as TR-galectin because of the two CRD structures. The deduced amino acid sequence of Tsgal had $97.1 \%$ identity with the galectin of T. nativa, while the Tsgal had $22.1 \%$ with galectin- 6 of mice and $20.8 \%$ identity with galectin- 8 of human. It is speculated that the Tsgal from T. spiralis cuticles may mimic the galectins of the host as galectin homologues to perform similar function of the mammals.

Western blot results revealed that the native Tsgal protein was identified in somatic proteins of all $T$. spiralis lifecycle stages (ML, IIL, 3 and 6 days AW, and NBL) by anti-Tsgal serum, demonstrating the Tsgal is a somatic protein component of the parasite. RT-PCR results revealed that Tsgal transcription was observed at all $T$. spiralis phases (ML, IIL, 3 and 6 days AW, and NBL). The IFA results revealed that Tsgal expression was detected at all T. spiralis various stages, immunostaining was primarily distributed at the surfaces, cuticles, stichosomes and embryos of this nematode. The results suggested that the Tsgal might play some roles as a Trichinella surface protein for larval invasion of host's small intestine [38]. Parasite surface proteins are directly exposed to the host's immune system and are the pivotal target antigenic molecules. Moreover, the some worm surface proteins may interact with the host to modify the nematode itself and its environment by modulating host's immune response for immune evasion or even regulating host cell gene 


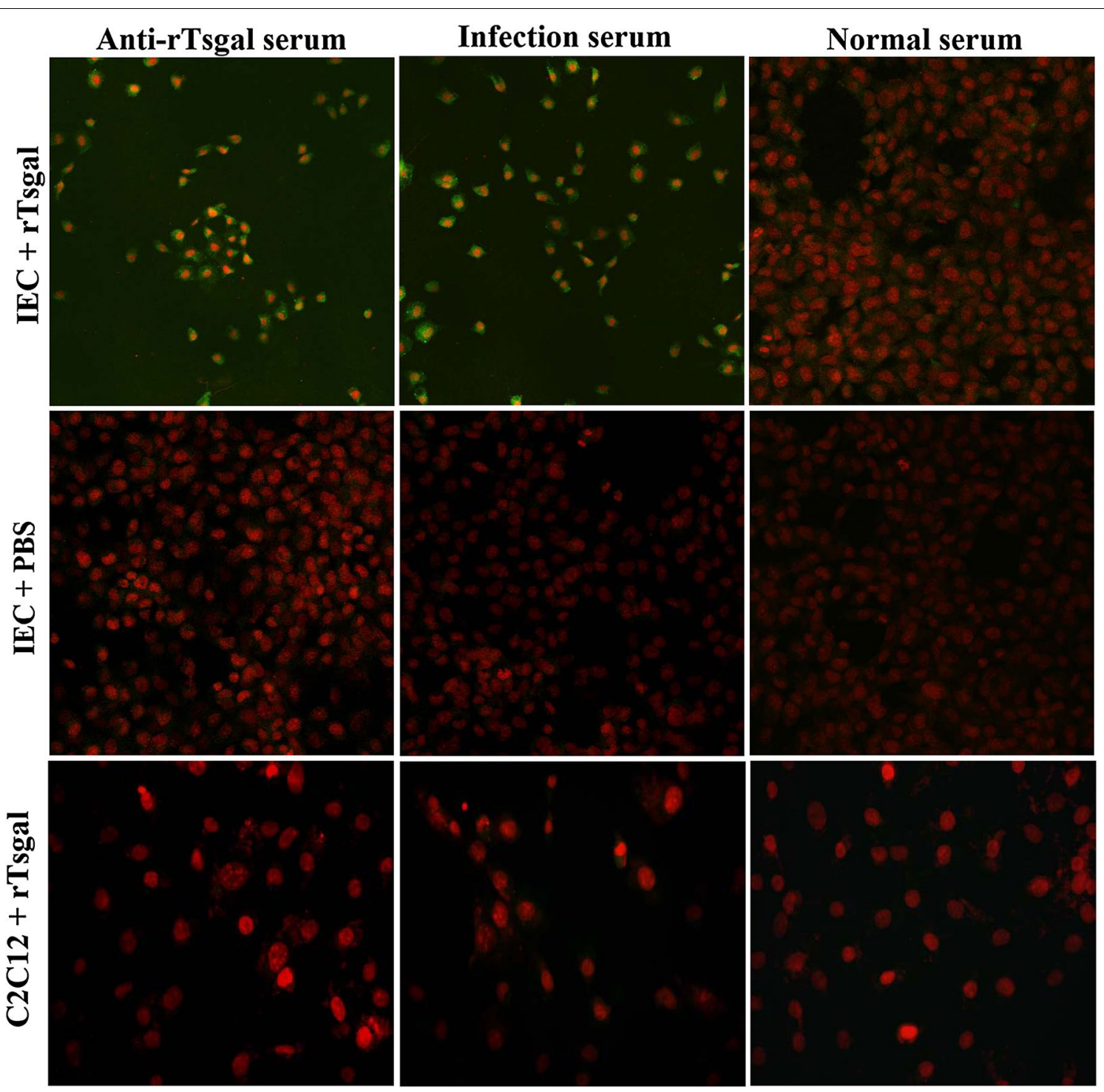

Figure 8 Immunofluorescent assay of rTsgal binding to IECs $(x \mathbf{2 0 0})$. The IECs were pre-incubated with rTsgal or PBS, the C2C12 s were pre-incubated with rTsgal at $37^{\circ} \mathrm{C}$ for $2 \mathrm{~h}$. Then, IECs were probed by anti-rTsgal serum, infection serum or normal serum, finally stained by using anti-mouse IgG-FITC conjugate, and the cell nuclei were dyed red with propidium iodide.

expression (such as skeletal muscle myogenesis, development and regeneration), to conduce to the larval invasion, development and survival [59-61].

In the process of larval invasion of the host intestinal mucosa, some proteins secreted from intestinal parasites bond to enterocytes. These proteins may play some functions in the interaction between parasites and host and benefit the parasite survival. Previous studies demonstrated nudix hydrolase secreted by T. spiralis (TsNd) bond specifically to the membranes of IECs and facilitated larval invasion and development
[29]. Our results of far Western blot confirmed the protein interaction between rTsgal and IECs, ten protein bands of IEC lysates pre-incubated with rTsgal were probed by anti-rTsgal serum. The results of IFA and confocal microscopy indicated that the rTsgal specifically bound to IECs, and the binding sites were located at the membrane and cytoplasm of the IECs. The IEC proteins binding with Tsgal need to be characterized in further experiment. The CRD of Entamoeba histolytica Gal/GalNAC lectin was reported to bind to TLR2 and TLR4 in human colonic cells, and activated their signal 


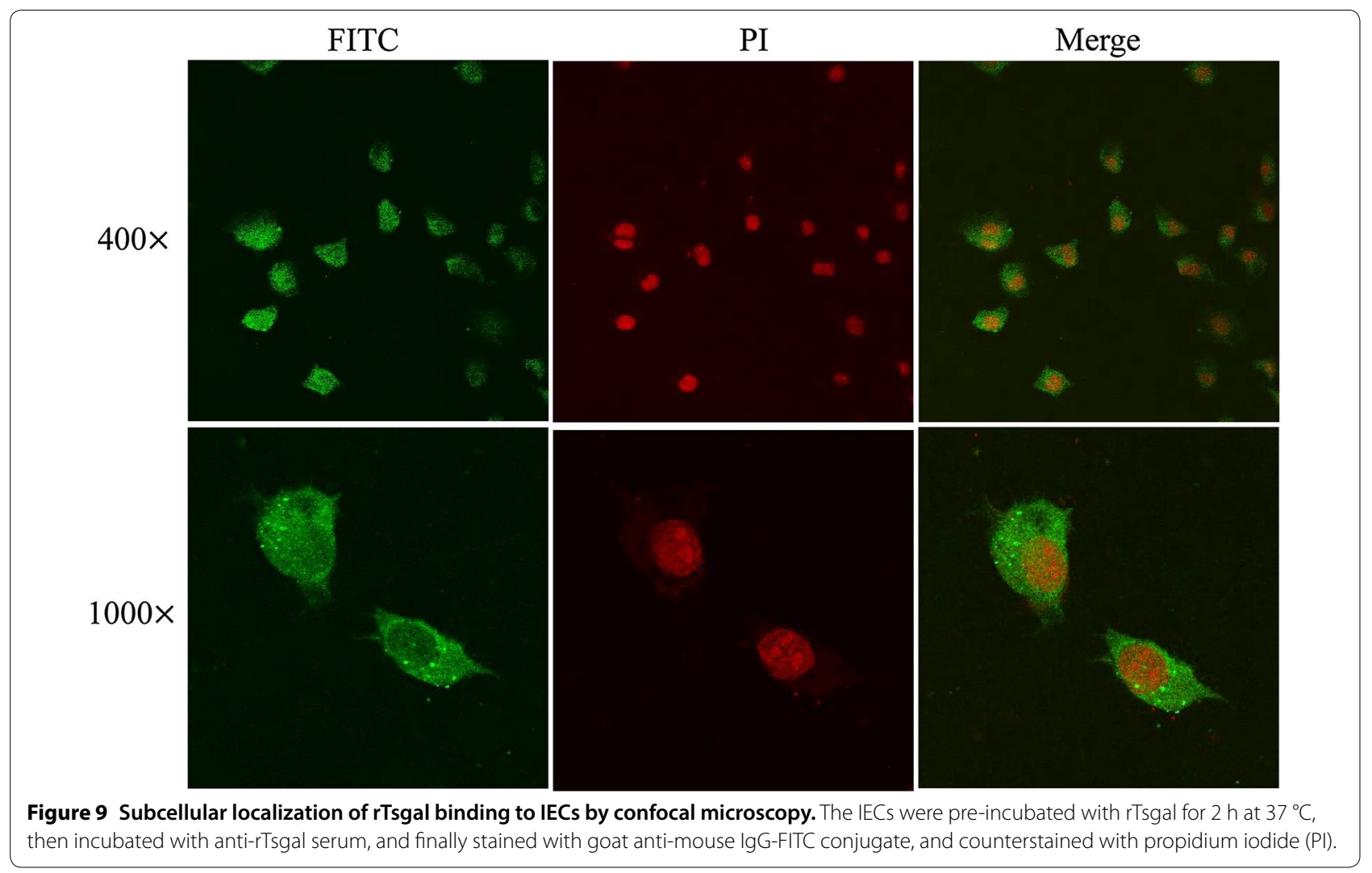

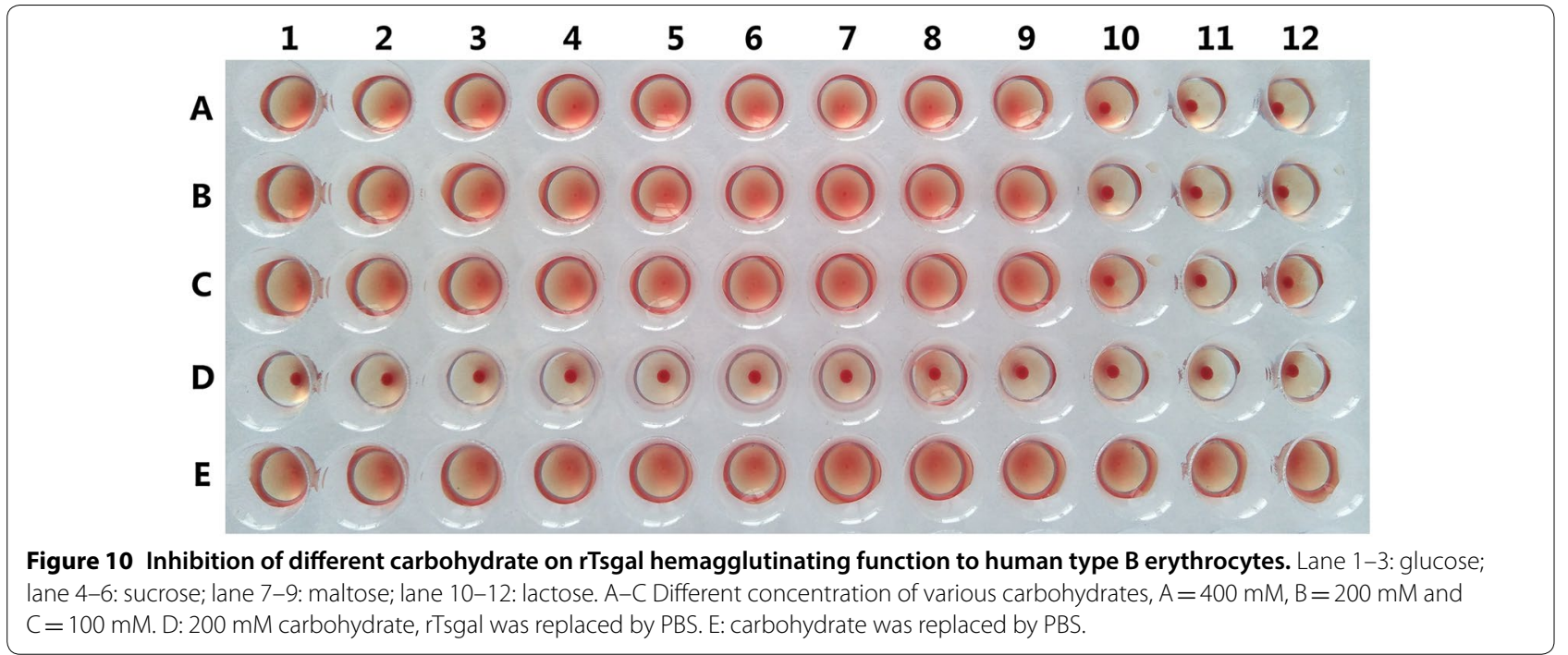

pathway and then enhanced adhesion of trophozoites to the cells [62]. The galectin from $H$. contortus was identified to have function in immune system by binding with glycoproteins on PBMC, and the glycoproteins may play an important part in cell migration, phagocytosis, and the secretion of the cytokines [63].
The hemagglutination activity of rTsgal was also identified in our study. The rTsgal displayed hemagglutinating activities for four kinds of erythrocytes (A, B, $\mathrm{O} A B$ types) of humans as well as those of rabbit and mice. For agglutinating to human type B erythrocytes, the minimum concentration of rTsgal was $40 \mu \mathrm{g} / \mathrm{mL}$, 


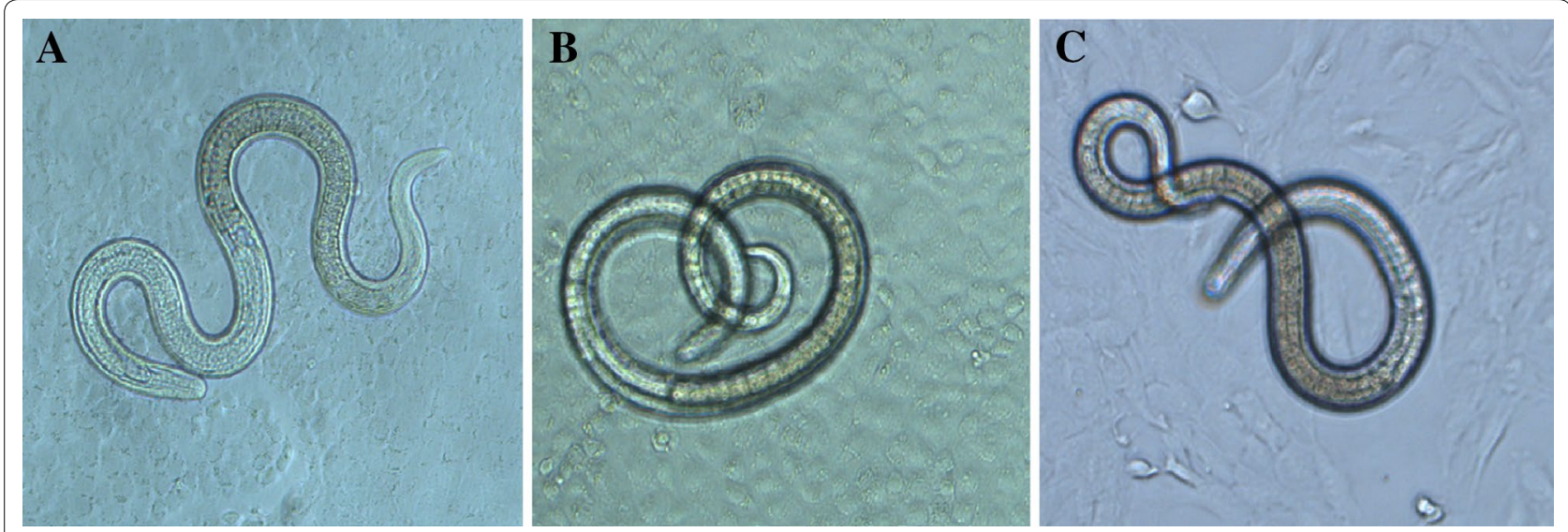

Figure 11 The invasion process of the IEC monolayer by T. spiralis larvae. The larvae are inoculated onto the IECS and the invasion process was observed under microscope at $2 \mathrm{~h}$ after incubation. A Larva invaded the IEC monolayer was mobile and its migrating trail was observed. B Non-invaded larva was coiled. C Non-invaded larva in C2C12 monolayer.
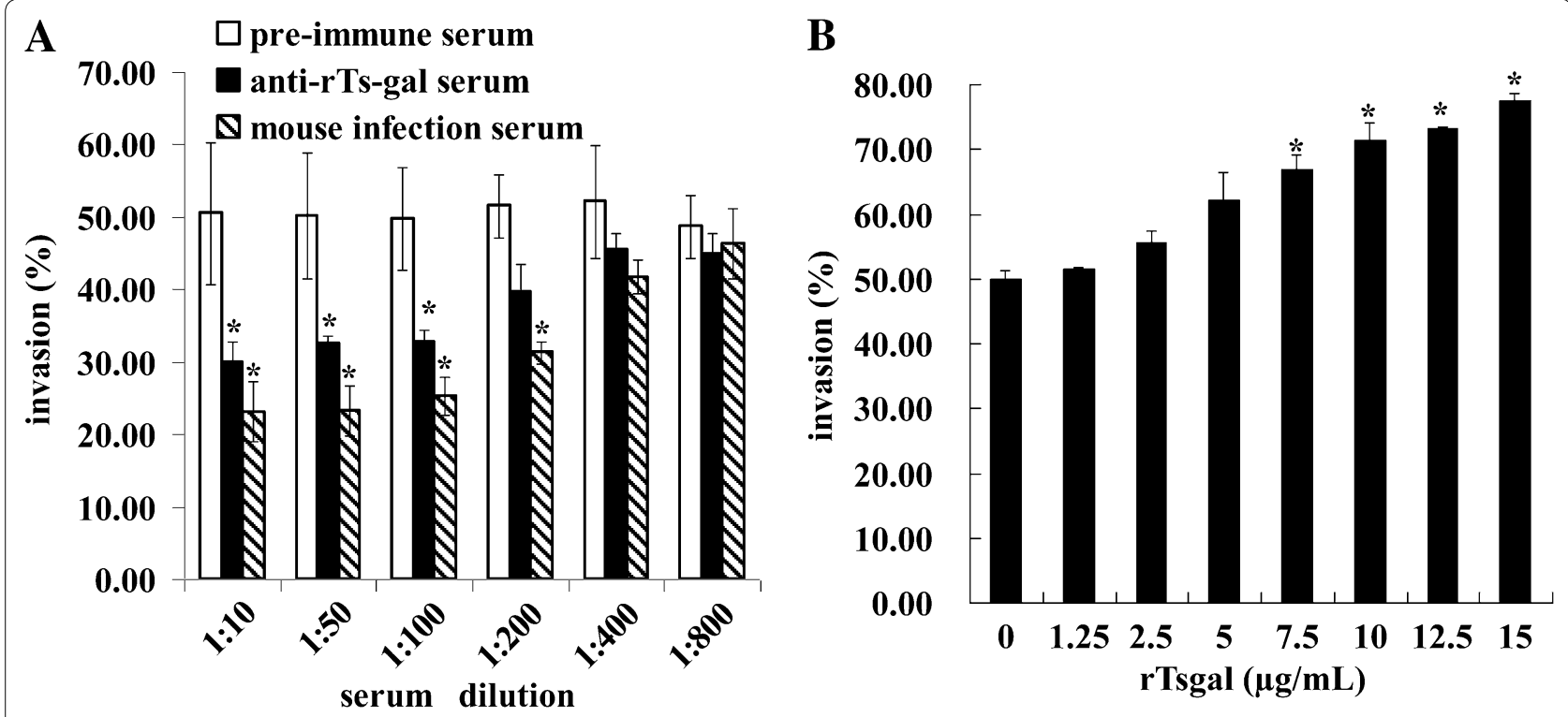

Figure 12 The inhibition or promotion of T. spiralis larval invasion of IEC monolayer by anti-rTsgal serum or rTsgal. A Inhibition of larval invasion of monolayer by anti-rTsgal serum. One hundred larvae were added into medium and then covered the cell monolayer, different dilutions of anti-rTsgal serum, infection serum or normal serum was used in this experiment and the larval invasion rate was observed $2 \mathrm{~h}$ after incubation. B The promotion of larvae invasion of IEC monolayer by rTsgal. Different dose of the rTsgal was added into medium, the larval invasion was observed $2 \mathrm{~h}$ after cultivation. The larval invasion rate is expressed as the percentages of the larvae penetrated into monolayer and shown as the mean \pm SD of three independent experiments. Significant differences $(P<0.01)$ were marked with asterisks $\left.{ }^{*}\right)$ relative to normal serum group or control group without rTsgal.

while the lowest dose of Toxascaris leonine galectin is $62.5 \mu \mathrm{g} / \mathrm{mL}$, and the mouse galectin is $20 \mu \mathrm{g} / \mathrm{mL}$ [20]. Although the carbohydrate binding ability of rTsgal is not very prominent, the carbohydrate-binding activity of rTsgal was exited and further confirmed by sugar inhibiting assay. Out of four carbohydrates, lactose was the only carbohydrate which inhibited the agglutination of human type B erythrocytes by rTsgal. The rTsgal specially binding to lactose was most likely related with their structure [56].

In addition, the results of in vitro invasion assay revealed that $r$ Tsgal facilitated the larval invasion of IECs, while anti-rTsgal antibodies inhibited the larval invasion in a dose-dependent mode. The facilitation is 
likely connected with the tissue structure changes by degrading the ECM of IECs or activating the cell signal pathways, which assisted in parasite invasion of the host's cells, as the galectins of D. immitis and E. histolytica $[18,62]$. It has been reported that some antibodies against recombinant Trichinella proteins protected the intestinal epithelium from larval invasion [34, 49, $64,65]$. The inhibition mechanism of larval invasion of IECs could be owing to the formation immune complex of Tsgal and anti-Tsgal antibody in larval cephalosome, which physically blocked the direct contact between the larvae and host's cells, and inhibited the larval invasion $[66,67]$. The in vivo biological function of the Tsgal need to be further investigated in animal experiment.

In conclusion, the Tsgal was expressed during all $T$. spiralis various phases and located mainly in the surfaces, cuticles and stichosomes of this nematode. The rTsgal had hemagglutinating activities to erythrocytes and bond specifically to IEC membrane and cytoplasm. The rTsgal protein could promote the larval invasion of IEC monolayer, while the anti-rTsgal serum inhibited the larval invasion of the monolayer in dose-dependent mode. These results indicated that the Tsgal might interact with IECs and participate in T. spiralis invasion of host's intestinal epithelium in early infection stage.

\begin{abstract}
Abbreviations
AW: adult worms; CRD: carbon recognized domain; dpi: days post-infection; DAB: 3, 3'-diaminobenzidine tetrahydrochloride; DSS: dextran sodium sulfate; ECM: extracellular matrix; ES: excretory-secretory; G3PDH: glyceraldehyde 3-phosphate dehydrogenase; hpi: hour post-infection; IBD: inflammatory bowel disease; IEC: intestinal epithelial cell; IFA: immunofluorescent assay; IIL: intestinal infective larvae; IPTG: isopropyl $\beta$-D-1-thiogalactopyranoside; ML: muscle larvae; NBL: newborn larvae; OPD: o-phenylenediamine dihydrochloride; PI: propidium iodide; PVDF: polyvinylidene difluoride; SD: standard deviation; TBS: tris-buffered saline; Tsgal: Trichinella spiralis galectin; TsNd: T. spiralis nudix hydrolase.
\end{abstract}

\section{Competing interests}

The authors declare that they have no competing interests.

\section{Authors' contributions}

$J C$ and ZQW designed this study. JX, FY, DQY, PJ, RDL and XZ performed the experiments. JX analyzed the data with assistance of PJ and RDL. JX, JC and ZQW wrote the manuscript. All authors read and approved the final manuscript.

\section{Acknowledgements}

This study was supported by grants of the National Natural Science Foundation of China (U1704284 and 81672043).

\section{Ethics approval and consent to participate}

The use of animals and experimental protocols in this study were approved by the Life Science Ethics Committee, Zhengzhou University (No. SCXK 2015-0005).

\section{Author details}

${ }^{1}$ Department of Parasitology, Medical College, Zhengzhou University, Zhengzhou 450052, China. ${ }^{2}$ School of Life Science, Zhengzhou University, Zhengzhou 450052, China.

\section{Publisher's Note}

Springer Nature remains neutral with regard to jurisdictional claims in published maps and institutional affiliations.

Received: 11 May 2018 Accepted: 11 July 2018

Published online: 02 August 2018

\section{References}

1. Cui J, Wang ZQ (2011) An epidemiological overview of swine trichinellosis in China. Vet J 190:323-328

2. Pozio E (2007) World distribution of Trichinella spp. infections in animals and humans. Vet Parasitol 149:3-21

3. Cui J, Wang ZQ, Xu BL (2011) The epidemiology of human trichinellosis in China during 2004-2009. Acta Trop 118:1-5

4. Jiang $P$, Zhang X, Wang LA, Han LH, Yang M, Duan JY, Sun GG, Qi X, Liu RD, Wang ZQ, Cui J (2016) Survey of Trichinella infection from domestic pigs in the historical endemic areas of Henan province, central China. Parasitol Res 115:4707-4709

5. Sequeira GJ, Zbrun MV, Soto LP, Astesana DM, Blajman JE, Rosmini MR, Frizzo LS, Signorini ML (2016) Quantitative risk assessment of human trichinellosis caused by consumption of Pork meat Sausages in Argentina. Zoonoses Public Health 63:167-176

6. Ribicich M, Gamble HR, Rosa A, Bolpe J, Franco A (2005) Trichinellosis in Argentina: an historical review. Vet Parasitol 132:137-142

7. Murrell KD, Pozio E (2011) Worldwide occurrence and impact of human trichinellosis, 1986-2009. Emerg Infect Dis 17:2194-2202

8. Bai X, Hu X, Liu X, Tang B, Liu M (2017) Current research of trichinellosis in China. Front Microbiol 8:1472

9. GuY, Sun X, Li B, Huang J, Zhan B, Zhu X (2017) Vaccination with a paramyosin-based multi-epitope vaccine elicits significant protective immunity against Trichinella spiralis Infection in Mice. Front Microbiol 8:1475

10. Gagliardo LF, McVay CS, Appleton JA (2002) Molting, ecdysis, and reproduction of Trichinella spiralis are supported in vitro by intestinal epithelial cells. Infect Immun 70:1853-1859

11. Wang L, Wang ZQ, Cui J (2013) Protein changes in Trichinella spiralis muscle larvae in vitro induced by bovine bile. Vet Parasitol 194:164-167

12. Despommier DD (1983) Biology. In: Campbell WC (ed) Trichinella and trichinosis. Plenum Press, New York, pp 75-151

13. Dupouy-Camet J, Kociecka W, Bruschi F, Bolas-Fernandez F, Pozio E (2002) Opinion on the diagnosis and treatment of human trichinellosis. Expert Opin Pharmacother 3:1117-1130

14. Li LG, Wang ZQ, Liu RD, Yang X, Liu LN, Sun GG, Jiang P, Zhang X, Zhang GY, Cui J (2015) Trichinella spiralis: low vaccine potential of glutathione S-transferase against infections in mice. Acta Trop 146:25-32

15. Hirabayashi J, Kasai K (1993) The family of metazoan metal-independent beta-galactoside-binding lectins: structure, function and molecular evolution. Glycobiology 3:297-304

16. Vasta GR (2009) Roles of galectins in infection. Nat Rev Microbiol 7:424-438

17. Vasta GR (2012) Galectins as pattern recognition receptors: structure, function, and evolution. Adv Exp Med Biol 946:21-36

18. Gonzalez-Miguel J, Larrazabal C, Loa-Meson D, Siles-Lucas M, Simon F, Morchon R (2016) Glyceraldehyde 3-phosphate dehydrogenase and galectin from Dirofilaria immitis participate in heartworm disease endarteritis via plasminogen/plasmin system. Vet Parasitol 223:96-101

19. Bing SJ, Ha D, Ahn G, Cho J, Kim A, Park SK, Yu HS, Jee Y (2015) Galectin isolated from parasite inhibits remission of experimental autoimmune encephalomyelitis by up-regulating autoantibody. Clin Exp Immunol 180:419-431

20. Kim JY, Cho MK, Choi SH, Lee KH, Ahn SC, Kim DH, Yu HS (2010) Inhibition of dextran sulfate sodium (DSS)-induced intestinal inflammation via enhanced IL-10 and TGF-beta production by galectin- 9 homologues isolated from intestinal parasites. Mol Biochem Parasitol 174:53-61

21. Liu LH, He HJ, Lv ZY, Wei J, Zeng X, Liang JY, Zheng HQ, Yu XB, Sun X, Wu ZD (2013) The mRNA level of the galectin-10 of Angiostrongylus cantonensis induced by reactive oxygen stress. Parasitol Res 112:933-943 
22. Yanming S, Ruofeng Y, Muleke Cl, Guangwei Z, Lixin X, Xiangrui L (2007) Vaccination of goats with recombinant galectin antigen induces partial protection against Haemonchus contortus infection. Parasit Immunol 29:319-326

23. Cui J, Liu RD, Wang L, Zhang X, Jiang P, Liu MY, Wang ZQ (2013) Proteomic analysis of surface proteins of Trichinella spiralis muscle larvae by twodimensional gel electrophoresis and mass spectrometry. Parasit Vectors 6:355

24. Liu RD, Cui J, Liu XL, Jiang P, Sun GG, Zhang X, Long SR, Wang L, Wang ZQ (2015) Comparative proteomic analysis of surface proteins of Trichinella spiralis muscle larvae and intestinal infective larvae. Acta Trop 150:79-86

25. Liu LN, Wang ZQ, Zhang X, Jiang P, Zhang ZF, Zhang GY, Cui J (2015) Analysis of structure, function and epitopes of Spirometra erinaceieuropaei casein kinase I. Trop Biomed 32:167-175

26. Zhang YLZH, Zhang X, Liu LN, Liu RD, Xu BL, Wang ZQ, Cui J (2015) Analysis of structures, functions, and epitopes of aminopeptidase from Trichinella spiralis. Trop Biomed 32:776-782

27. Tamura K, Peterson D, Peterson N, Stecher G, Nei M, Kumar S (2011) MEGA5: molecular evolutionary genetics analysis using maximum likelihood, evolutionary distance, and maximum parsimony methods. Mol Biol Evol 28:2731-2739

28. Ren HJ, Cui J, Wang ZQ, Liu RD (2011) Normal mouse intestinal epithelial cells as a model for the in vitro invasion of Trichinella spiralis infective larvae. PLoS One 6:e27010

29. Long SR, Wang ZQ, Jiang P, Liu RD, Qi X, Liu P, Ren HJ, Shi HN, Cui J (2015) Characterization and functional analysis of Trichinella spiralis Nudix hydrolase. Exp Parasitol 159:264-273

30. Li F, Cui J, Wang ZQ, Jiang P (2010) Sensitivity and optimization of artificial digestion in the inspection of meat for Trichinella spiralis. Foodborne Pathog Dis 7:879-885

31. Wu Z, Nagano I, Takahashi Y, Maekawa Y (2016) Practical methods for collecting Trichinella parasites and their excretory-secretory products. Parasitol Int 65:591-595

32. Yang Y, Lacour SA, Laine-Prade V, Versille N, Grasset-Chevillot A, Feng S, Liu MY, Boireau P, Vallee I (2015) Trichinella spiralis newborn larvae: characterization of a stage specific serine proteinase expression, NBL1, using monoclonal antibodies. Parasitology 142:783-790

33. Wang L, Cui J, Hu DD, Liu RD, Wang ZQ (2014) Identification of early diagnostic antigens from major excretory-secretory proteins of Trichinella spiralis muscle larvae using immunoproteomics. Parasit Vectors 7:40

34. Wang B, Wang ZQ, Jin J, Ren HJ, Liu LN, Cui J (2013) Cloning, expression and characterization of a Trichinella spiralis serine protease gene encoding a $35.5 \mathrm{kDa}$ protein. Exp Parasitol 134:148-154

35. Bradford MM (1976) A rapid and sensitive method for the quantitation of microgram quantities of protein utilizing the principle of protein-dye binding. Anal Bochem 72:248-254

36. Liu CY, Song YY, Ren HN, Sun GG, Liu RD, Jiang P, Long SR, Zhang X, Wang ZQ, Cui J (2017) Cloning and expression of a Trichinella spiralis putative glutathione S-transferase and its elicited protective immunity against challenge infections. Parasit Vectors 10:448

37. Wang ZQ, Wang L, Cui J (2012) Proteomic analysis of Trichinella spiralis proteins in intestinal epithelial cells after culture with their larvae by shotgun LC-MS/MS approach. J Proteomics 75:2375-2383

38. Liu RD, Cui J, Wang L, Long SR, Zhang X, Liu MY, Wang ZQ (2014) Identification of surface proteins of Trichinella spiralis muscle larvae using immunoproteomics. Trop Biomed 31:579-591

39. Liu RD, Qi X, Sun GG, Jiang P, Zhang X, Wang LA, Liu XL, Wang ZQ, Cui $J$ (2016) Proteomic analysis of Trichinella spiralis adult worm excretory-secretory proteins recognized by early infection sera. Vet Parasitol 231:43-46

40. Yang W, Li LG, Liu RD, Sun GG, Liu CY, Zhang SB, Jiang P, Zhang X, Ren HJ, Wang ZQ, Cui J (2015) Molecular identification and characterization of Trichinella spiralis proteasome subunit beta type-7. Parasit Vectors 8:18

41. Zhang NZ, Liu JY, Li WH, Li L, Qu ZG, Li TT, Cui JM, Yang Y, Jia WZ, Fu BQ (2016) Cloning and characterization of thioredoxin peroxidases from Trichinella spiralis. Vet Parasitol 231:53-58

42. Cui J, Wang L, Sun GG, Liu LN, Zhang SB, Liu RD, Zhang X, Jiang P, Wang ZQ (2015) Characterization of a Trichinella spiralis $31 \mathrm{kDa}$ protein and its potential application for the serodiagnosis of trichinellosis. Acta Trop 142:57-63
43. Wang SW, Wang ZQ, Cui J (2011) Protein change of intestinal epithelial cells induced in vitro by Trichinella spiralis infective larvae. Parasitol Res 108:593-599

44. Long SR, Wang ZQ, Liu RD, Liu LN, Li LG, Jiang P, Zhang X, Zhang ZF, Shi HN, Cui I (2014) Molecular identification of Trichinella spiralis nudix hydrolase and its induced protective immunity against trichinellosis in BALB/C mice. Parasit Vectors 7:600

45. Wang ZQ, Liu RD, Sun GG, Song YY, Jiang P, Zhang X, Cui J (2017) Proteomic analysis of Trichinella spiralis adult worm excretory-secretory proteins recognized by sera of patients with early trichinellosis. Front Microbiol 8:986

46. Francischetti IM, Ma D, Andersen JF, Ribeiro JM (2014) Evidence for a lectin specific for sulfated glycans in the salivary gland of the malaria vector, Anopheles gambiae. PLoS One 9:e107295

47. Yoshino TP, Dinguirard N, Kunert J, Hokke CH (2008) Molecular and functional characterization of a tandem-repeat galectin from the freshwater snail Biomphalaria glabrata, intermediate host of the human blood fluke Schistosoma mansoni. Gene 411:46-58

48. Li C, Wei X, Xu L, Li X (2007) Recombinant galectins of male and female Haemonchus contortus do not hemagglutinate erythrocytes of their natural host. Vet Parasitol 144:299-303

49. Cui J, Li LG, Jiang P, Liu RD, Yang X, Liu LN, Liu P, Zhang SB, Wang ZQ (2015) Biochemical and functional characterization of the glutathione S-transferase from Trichinella spiralis. Parasitol Res 114:2007-2013

50. ManWarren T, Gagliardo L, Geyer J, McVay C, Pearce-Kelling S, Appleton J (1997) Invasion of intestinal epithelia in vitro by the parasitic nematode Trichinella spiralis. Infect Immun 65:4806-4812

51. Zhang $S B$, Jiang $P$, Wang ZQ, Long SR, Liu RD, Zhang X, Yang W, Ren HJ, Cui I (2016) DsRNA-mediated silencing of Nudix hydrolase in Trichinella spiralis inhibits the larval invasion and survival in mice. Exp Parasitol 162:35-42

52. Souza BM, Lambert SM, Nishi SM, Benavides MV, Berne ME, Madruga CR, Almeida MA (2015) Galectins and collectinis expression are increased in Haemonchus contortus-infected corriedale sheep. Rev Bras Parasitol Vet 24:317-323

53. Pelletier I, Sato S (2002) Specific recognition and cleavage of galectin-3 by Leishmania major through species-specific polygalactose epitope. J Biol Chem 277:17663-17670

54. Wu XJ, Dinguirard N, Sabat G, Lui HD, Gonzalez L, Gehring M, BickhamWright U, Yoshino TP (2017) Proteomic analysis of Biomphalaria glabrata plasma proteins with binding affinity to those expressed by early developing larval Schistosoma mansoni. PLoS Pathog 13:e1006081

55. Greenhalgh CJ, Newton SE (1999) Recombinant expression of a galectin from the sheep gastrointestinal parasite Teladorsagia circumcincta: its use in isolating galectin-glycoconjugates. Protein Expr Purif 16:152-159

56. Hwang EY, Jeong MS, Park SK, Ha SC, Yu HS, Jang SB (2016) Structural basis for carbohydrate recognition and anti-inflammatory modulation by gastrointestinal nematode parasite Toxascaris leonina galectin. J Biol Chem 291:25326-25338

57. Newton SE, Monti JR, Greenhalgh CJ, Ashman K, Meeusen EN (1997) cDNA cloning of galectins from third stage larvae of the parasitic nematode Teladorsagia circumcincta. Mol Biochem Parasitol 86:143-153

58. Cleves AE, Cooper DN, Barondes SH, Kelly RB (1996) A new pathway for protein export in Saccharomyces cerevisiae. J Cell Biol 133:1017-1026

59. Bolas-Fernandez F, Corral Bezara LD (2006) TSL-1 antigens of Trichinella: an overview of their potential role in parasite invasion, survival and serodiagnosis of trichinellosis. Res Vet Sci 81:297-303

60. Nagano I, Wu Z, Takahashi Y (2009) Functional genes and proteins of Trichinella spp. Parasitol Res 104:197-207

61. Wu Z, Nagano I, Takahashi Y (2008) Candidate genes responsible for common and different pathology of infected muscle tissues between Trichinella spiralis and T. pseudospiralis infection. Parasitol Int 57:368-378

62. Galvan-Moroyoqui JM, Del Carmen Dominguez-Robles M, Meza I (2011) Pathogenic bacteria prime the induction of Toll-like receptor signalling in human colonic cells by the Gal/GalNAc lectin carbohydrate recognition domain of Entamoeba histolytica. Int J Parasitol 41:1101-1112

63. Yuan C, Zhang H, Wang W, Li Y, Yan R, Xu L, Song X, Li X (2015) Transmembrane protein $63 \mathrm{~A}$ is a partner protein of Haemonchus contortus galectin in the regulation of goat peripheral blood mononuclear cells. Parasit Vectors 8:211 
64. Liu CY, Ren HN, Song YY, Sun GG, Liu RD, Jiang P, Long SR, Zhang X, Wang ZQ, Cui J (2018) Characterization of a putative glutathione S-transferase of the parasitic nematode Trichinella spiralis. Exp Parasitol 187:59-66

65. Sun GG, Ren HN, Liu RD, Song YY, Qi X, Hu CX, Yang F, Jiang P, Zhang X, Wang ZQ, Cui J (2018) Molecular characterization of a putative serine protease from Trichinella spiralis and its elicited immune protection. Vet Res 49:59
66. McVay CS, Tsung A, Appleton J (1998) Participation of parasite surface glycoproteins in antibody-mediated protection of epithelial cells against Trichinella spiralis. Infect Immun 66:1941-1945

67. McVay CS, Bracken P, Gagliardo LF, Appleton J (2000) Antibodies to tyvelose exhibit multiple modes of interference with the epithelial niche of Trichinella spiralis. Infect Immun 68:1912-1918
Ready to submit your research? Choose BMC and benefit from:

- fast, convenient online submission

- thorough peer review by experienced researchers in your field

- rapid publication on acceptance

- support for research data, including large and complex data types

- gold Open Access which fosters wider collaboration and increased citations

- maximum visibility for your research: over $100 \mathrm{M}$ website views per year

At BMC, research is always in progress.

Learn more biomedcentral.com/submissions 